\title{
Home Range and Habitat Use of the New Zealand Falcon (Falco novaeseelandiae) within a Plantation Forest: A Satellite Tracking Study
}

\author{
Bindi Thomas, Edward O. Minot, and John D. Holland \\ Institute of Natural Resources, Massey University, Private Bag 11-222, Palmerston North, New Zealand \\ Correspondence should be addressed to Bindi Thomas, bindi.thomas.1@uni.massey.ac.nz
}

Received 21 April 2010; Accepted 29 June 2010

Academic Editor: Bruce Leopold

Copyright () 2010 Bindi Thomas et al. This is an open access article distributed under the Creative Commons Attribution License, which permits unrestricted use, distribution, and reproduction in any medium, provided the original work is properly cited.

\begin{abstract}
We tracked two adult and three juvenile New Zealand falcons (Falco novaeseelandiae) in Kaingaroa Forest pine plantation from 2002 to 2008 using Argos satellite technology. The home ranges for both adults and juveniles varied, ranging between 44 and $587 \mathrm{~km}^{2}$. The falcons occasionally utilised areas outside the forest and used stands of all ages within the forest, generally in proportion to their availability. For the most part, the juveniles remained within ca. $8 \mathrm{~km}$ of their nests and dispersed at 58,69 , and 68 days after fledging. Falcon movement information was obtained from an average of four location points per tracking day per falcon at a putative accuracy of $350 \mathrm{~m}$. The transmitters, including their solar charge capability, performed well in the forest environment. The use of all stand ages highlights the importance of forestry practises that maintain a mosaic of different aged pine stands.
\end{abstract}

\section{Introduction}

Protected since 1974 and classified as "Nationally Vulnerable" [1], the New Zealand falcon (Falco novaeseelandiae) is the country's only endemic bird of prey. There are three identified forms distinguishable by their plumage, size, range, and habitat preference [2], the Bush (c.1300 pairs), Southern (c.400 pairs), and Eastern (c.3150 pairs) forms [3].

Destruction of the New Zealand falcon's habitat is reported to be a key factor leading to the species' decline [3]. Historically, the Bush form has bred in tall podocarp forests [4], however, following extensive logging, falcons have been found nesting in clear-cut compartments of pine plantations within the Central North Island $[4,5]$. Understanding more about the use of pine forests by falcons in New Zealand is of conservation importance. Plantation forests, if managed appropriately, may provide a suitable habitat for the recovery of this species [6].

Until recently, there has been little research on this species. Fox [7] studied the biology of the Eastern form identifying home range and habitat use within their range on the north-west coast of the South Island. More recent research has focused on the Bush form within exotic forest plantations $[8,9]$. Seaton [6] used ground-based VHF radio telemetry to study the home range, habitat use, and dispersal of falcons within Kaingaroa Forest. However, little is known about their year-round habitat use of falcons. This study assembles a long-term record of falcon movement within Kaingaroa Forest, that can be used to enhance policy and species management plans and to inform future researchers on the use of satellite technology for this species.

Argos satellite telemetry was identified as an effective tool for gathering long-term, continuous location data to map the falcons' use of specific areas. Holland and McCutcheon [8] undertook the first falcon satellite tracking study in New Zealand when they used an 18-g solar-powered satellite transmitter to monitor the movements of a 540-g female New Zealand falcon over a three-year period in Kaingaroa Forest. As an expansion of their pilot project, this paper updates their earlier work by reporting on the results from a further four satellite-tracked falcons in the same forest.

To assemble a long-term dataset and enhance our understanding of falcon movements and habitat use, we deployed five satellite transmitters for up to three years 
to monitor NZ falcons within Kaingaroa Forest. Specific objectives were to (1) quantify home range size, (2) determine seasonal home range patterns for adults, (3) determine selection of compartments of different ages, (4) describe the pattern of juvenile dispersal, and finally (5) evaluate the technical performance of the five transmitters under field conditions. We considered four components of performance: the number of locations obtained within each accuracy class, the efficiency of the duty cycle (preset on/off regime), the accuracy of the system, and the solar charging efficiency within this forest environment. This technical evaluation will aid in the interpretation of biological results to determine whether they functioned efficiently enough to underpin falcon management decisions.

\section{Materials and Methods}

Our study examines a breeding population of Bush falcons in Kaingaroa Forest, the oldest and largest softwood plantation forest in the world [10]. Located between Rotorua and Taupo on the volcanic plateau of New Zealand's central North Island, the 189,000-ha Kaingaroa Forest is a mosaic of approximately 1,400 intensively managed compartments of various-aged radiata pine (Pinus radiata). These compartments are mostly flat or gently sloping and are approximately 135 ha in size. Harvesting usually occurs at 25-30 years of age, followed by replanting within one year.

In this study, five solar powered Platform Transmitter Terminals (PTT), (Microwave Telemetry Inc., Columbia, Maryland, USA) were used to track falcon movements. PTT's are transmitters that send a signal via the Argos satellite system (C.L.S, Ramonville Saint-Agne, France). This system consists of polar orbiting satellites located $800 \mathrm{~km}$ above the earth equipped with Ultra High Frequency receivers. Each time the satellite passes over a PTT, it has approximately 10 minutes to calculate its location using the Doppler effect. The accuracy of each location point is assessed and assigned one of several Location Classes (LC). The standard deviation of positional error in latitudinal and longitudinal axes is claimed to be $150 \mathrm{~m}$ for LC 3, $350 \mathrm{~m}$ for LC 2, $1000 \mathrm{~m}$ for LC 1 , and $>1000 \mathrm{~m}$ for LC 0 [11]. When three or fewer messages are received by the satellite, the accuracy levels are LC A \& B (no estimation accuracy) or LC Z (invalid location). Only locations with an Argos specified accuracy of $<350 \mathrm{~m}$ (LC 3 and 2) were used for analysis.

Three of the PTT's were set to a 58-hour duty cycle ( $10 \mathrm{hrs}$ on/48 hrs off) and two set to a 34 -hour duty cycle ( $10 \mathrm{hrs}$ on/24 hrs off). The off part of the duty cycle helped to conserve the batteries and provide enough time for adequate recharging from the solar panel. The PTT cycles were offset from the 24-hour daily cycle to avoid transmission at the same time each day. On periods, therefore, occurred at different times of the day and alternated between nocturnal and diurnal transmissions.

Three juvenile and two adult falcons were captured at nesting sites within Kaingaroa Forest using Bal-chatri and Dho-gaza traps [12]. Male falcons weigh between 252-500 g and females between 420-594g (del Hoyo et al. 1994).
Twelve-gram PTT's were fitted to the juveniles and 18-g PTT's were fitted to the adults. Taking body weight into account, the transmitter weights were all less than $5 \%$ of the body mass of the falcons. Transmitters were attached to the back of the falcon with a 6-mm Teflon tube harness [13] using a standard backpack configuration.

Between February 2002 and August 2008, the falcon locations were downloaded from the Argos online data access system and maps were generated using a Geographic Information System (GIS) (ArcGIS ArcMap 9.2, Environmental Systems Research Institute, Redlands, California, USA). The data locations were recorded in latitude/longitude WGS84, and transformed to NZGD 2000 New Zealand Transverse Mercator for analysis.

The home ranges (MCP and Kernel) were calculated using the Animal Movement Analyst extension to ArcView [14]. MCP estimators are thought to overestimate space use [13]; however, they were used here to enable comparison with other studies and to map the maximum area potentially required by each falcon. A kernel-based home range utilising the $95 \%$ probability contour was used as a second measure to reduce outlier bias. The least-squares cross validation procedure was used to determine the smoothing parameter. We also used the kernel method to estimate compartment selection by identifying the compartments within each $95 \%$ kernel area, then calculated the age of each compartment and identified the number of falcon locations within them. Minitab 15.1.30.0 (C) 2007 Minitab Inc., State College, Pennsylvania, USA) was used for all statistical analysis. Unless otherwise noted, all means are expressed as the mean ( \pm s.d.).

\section{Results}

3.1. Falcon Movements. One male and one female adult falcon were continuously tracked for approximately three years. Three juvenile falcons, two male and one female, were tracked for approximately five months each.

The movements of the falcons and locations of their nest sites are presented in Figure 1. Their home range sizes are in Table 1. The juvenile female's $95 \%$ kernel home range was $44 \mathrm{~km}^{2}$ and the juvenile males' were 412 and $12 \mathrm{~km}^{2}$. Their MCP home ranges were 44,587 and $86 \mathrm{~km}^{2}$, respectively. The adult female utilised a $95 \%$ kernel home range of $90 \mathrm{~km}^{2}$ and MCP of $147 \mathrm{~km}^{2}$, with the adult male utilising an $8 \mathrm{~km}^{2}$ kernel home range and $61 \mathrm{~km}^{2} \mathrm{MCP}$. The kernel home range sizes during the nonbreeding and breeding seasons were compared for each adult falcon and were similar for both (Table 1).

All falcons except the adult male ranged beyond the Kaingaroa Forest boundaries. Six percent $(N=5)$ of the adult female locations registered outside the forest, with one location $13 \mathrm{~km}$ from the boundary, and the remaining within $2.5 \mathrm{~km}$ of it. The juvenile female ranged outside the forest approximately $9 \%(N=8)$ of the time, but all of these locations were within $3 \mathrm{~km}$ of the boundary. Juvenile male 2 was located outside the boundary $2 \%(N=3)$ of the time and was never further than $0.5 \mathrm{~km}$ from the boundary. Juvenile male 1, however, was tracked outside the Kaingaroa 

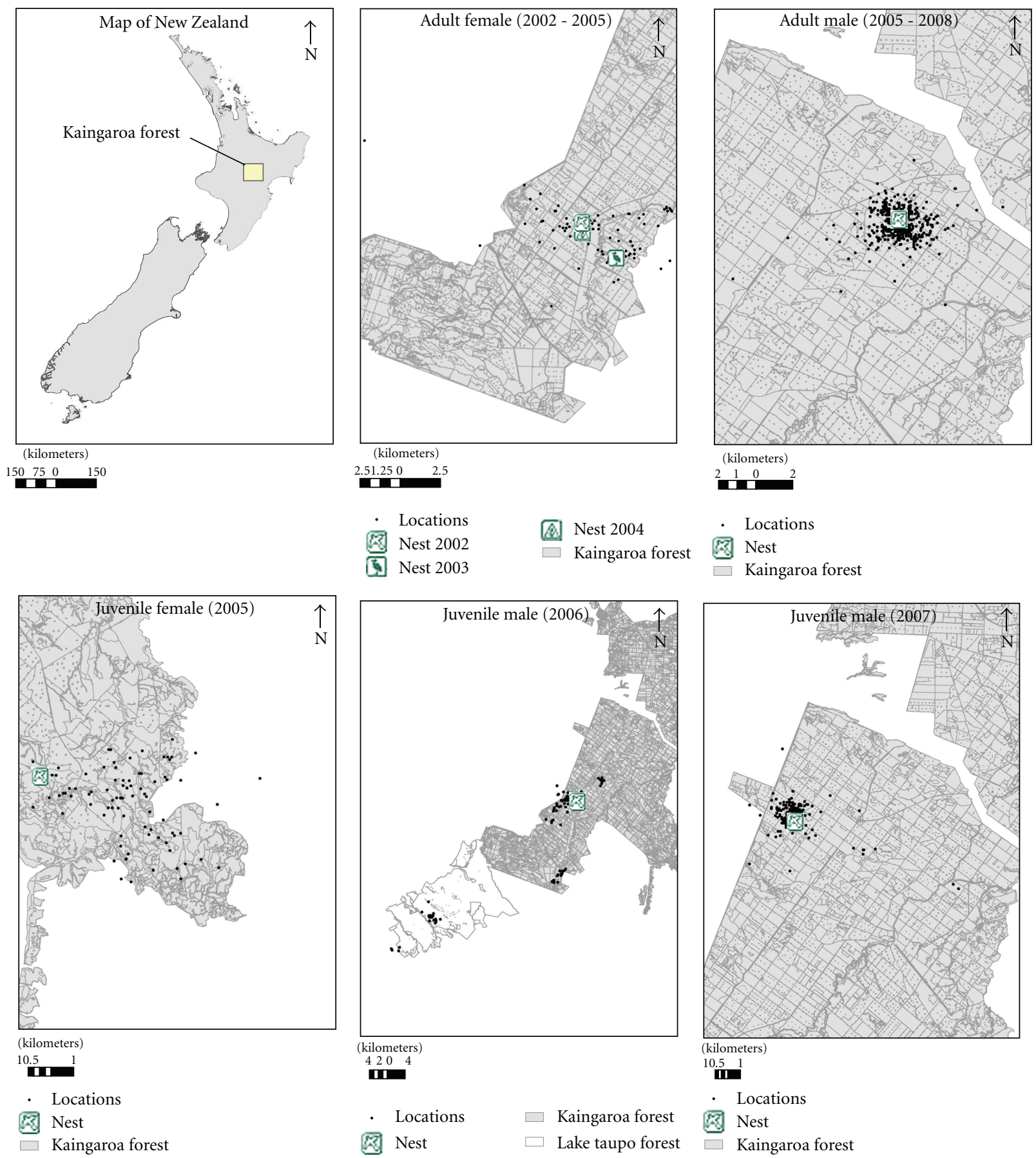

Figure 1: Locations and nest sites of two adult and three juvenile New Zealand falcons in Kaingaroa Forest, New Zealand.

forest boundary $24 \%(N=33)$ of the time, with the majority of these locations being approximately $50 \mathrm{~km}$ away in Lake Taupo Forest, a 33,000-ha pine plantation forest (Figure 1) managed by New Zealand Forest Managers (NZFM). This falcon made two separate trips to this forest, for a day in March and then again for the month of April 2006.

The juvenile female and juvenile male 2 remained within a distance of ca. $8 \mathrm{~km}$ from their nests for the duration of tracking, returning regularly to their nests (Figure 2).
Juvenile male 1 exhibited this same behaviour for the first two and a half months before leaving the nest area and travelling approximately $50 \mathrm{~km}$ over a two-day period to Lake Taupo Forest. He then returned to Kaingaroa Forest, but to an area approximately $16 \mathrm{~km}$ from his nest site.

For this paper, dispersal was calculated from when the juvenile left the adult home range. The radius of this adult home range (MCP) was between 4 and $6 \mathrm{~km}$. Using the $4 \mathrm{~km}$ radius, the number of days from fledging to when the three 
TABLE 1: MCP and kernel home range sizes.

\begin{tabular}{|c|c|c|c|c|c|c|c|}
\hline & \multirow{2}{*}{$\begin{array}{c}\mathrm{MCP}\left(\mathrm{km}^{2}\right) \\
100 \%\end{array}$} & \multirow{2}{*}{$\begin{array}{c}\text { Kernel }\left(\mathrm{km}^{2}\right) \\
95 \%\end{array}$} & \multirow[t]{2}{*}{ Year } & \multicolumn{2}{|c|}{ Nonbreeding $^{1}$} & \multicolumn{2}{|c|}{ Breeding $^{2}$} \\
\hline & & & & $95 \%^{3}$ & $50 \%{ }^{4}$ & $95 \%$ & $50 \%$ \\
\hline Juv female & 44 & 44 & $\mathrm{n} / \mathrm{a}$ & $\mathrm{n} / \mathrm{a}$ & $\mathrm{n} / \mathrm{a}$ & $\mathrm{n} / \mathrm{a}$ & $\mathrm{n} / \mathrm{a}$ \\
\hline Juv male 1 & 587 & 412 & $\mathrm{n} / \mathrm{a}$ & $\mathrm{n} / \mathrm{a}$ & $\mathrm{n} / \mathrm{a}$ & $\mathrm{n} / \mathrm{a}$ & $\mathrm{n} / \mathrm{a}$ \\
\hline \multirow[t]{2}{*}{ Juv male 2} & 86 & 12 & $\mathrm{n} / \mathrm{a}$ & $\mathrm{n} / \mathrm{a}$ & $\mathrm{n} / \mathrm{a}$ & $\mathrm{n} / \mathrm{a}$ & $\mathrm{n} / \mathrm{a}$ \\
\hline & \multirow{4}{*}{147} & \multirow{4}{*}{90} & 2002 & 52 & 11 & $\mathrm{n} / \mathrm{a}$ & $\mathrm{n} / \mathrm{a}$ \\
\hline \multirow{3}{*}{ Adult female ${ }^{5}$} & & & $2002 / 2003$ & $\mathrm{n} / \mathrm{a}$ & $\mathrm{n} / \mathrm{a}$ & 78 & 9 \\
\hline & & & 2003 & 41 & 10 & $\mathrm{n} / \mathrm{a}$ & $\mathrm{n} / \mathrm{a}$ \\
\hline & & & $2003 / 2004$ & $\mathrm{n} / \mathrm{a}$ & $\mathrm{n} / \mathrm{a}$ & 33 & 5 \\
\hline \multirow{4}{*}{ Adult male } & \multirow{4}{*}{61} & \multirow{4}{*}{8} & 2006 & 13 & 3 & $\mathrm{n} / \mathrm{a}$ & $\mathrm{n} / \mathrm{a}$ \\
\hline & & & $2006 / 2007$ & $\mathrm{n} / \mathrm{a}$ & $\mathrm{n} / \mathrm{a}$ & 10 & 1 \\
\hline & & & 2007 & 6 & 0.5 & $\mathrm{n} / \mathrm{a}$ & $\mathrm{n} / \mathrm{a}$ \\
\hline & & & $2007 / 2008$ & $\mathrm{n} / \mathrm{a}$ & $\mathrm{n} / \mathrm{a}$ & 6 & 0.7 \\
\hline
\end{tabular}

${ }^{1}$ Includes the months of April to September

${ }^{2}$ Includes the months of October to March

${ }^{3}$ Using the $95 \%$ kernel method

${ }^{4}$ Using the $50 \%$ kernel method

TABLE 2: Falcon use of compartments by age category.

\begin{tabular}{|c|c|c|c|c|c|c|c|c|c|}
\hline & \multirow[b]{2}{*}{ Year } & \multicolumn{2}{|c|}{$<4$ years } & \multicolumn{2}{|c|}{ 4-9 years } & \multicolumn{2}{|c|}{$10-19$ years } & \multicolumn{2}{|c|}{$>20$ years } \\
\hline & & Area $\left(\mathrm{km}^{2}\right)(\%)^{1}$ & Use $(\%)^{2}$ & Area $\left(\mathrm{km}^{2}\right)(\%)$ & Use $(\%)$ & Area $\left(\mathrm{km}^{2}\right)(\%)$ & Use $(\%)$ & Area $\left(\mathrm{km}^{2}\right)(\%)$ & Use (\%) \\
\hline Juv female & 2005 & 59 & 78 & 8 & 2 & 0 & 0 & 32 & 20 \\
\hline Juv male 1 & 2006 & 11 & 5 & 15 & 23 & 29 & 54 & 45 & 18 \\
\hline Juv male 2 & 2007 & 15 & 26 & 0 & 0 & 50 & 33 & 35 & 41 \\
\hline \multirow{3}{*}{ Adult female } & 2002 & 13 & 16 & 11 & 3 & 48 & 42 & 29 & 39 \\
\hline & 2003 & 16 & 18 & 8 & 3 & 44 & 38 & 32 & 41 \\
\hline & 2004 & 13 & 17 & 7 & 5 & 40 & 35 & 40 & 44 \\
\hline \multirow{3}{*}{ Adult male } & 2006 & 7 & 26 & 29 & 22 & 29 & 26 & 36 & 26 \\
\hline & 2007 & 3 & 1 & 32 & 45 & 32 & 28 & 32 & 24 \\
\hline & 2008 & 3 & 1 & 21 & 26 & 41 & 46 & 34 & 27 \\
\hline
\end{tabular}

${ }^{1}$ The compartments within each falcons' 95\% kernel home range were selected and the percentage of available area within each age group was calculated.

${ }^{2}$ The number of Argos locations within each compartment age was calculated as the percentage of use.

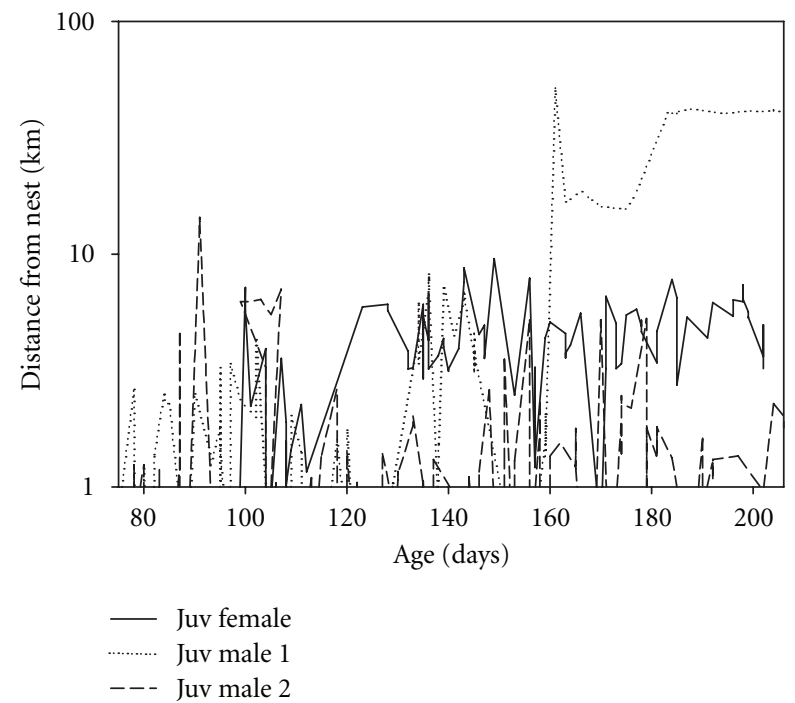

Figure 2: Distance from nest over time for juvenile falcons. juveniles dispersed from their natal territory was 68 days for the juvenile female and 69 and 58 days for juvenile male 1 and 2 , respectively.

Table 2 illustrates the falcons' use of compartments of different ages. It indicates the use of all compartments ages, used generally in proportion to their availability.

3.2. Performance of the Technology. The technical details for each PTT are presented in Table 3. Between $32 \%-54 \%$ of all recorded transmissions from the five PTT's were LC 3, 2, and $1(<1000 \mathrm{~m})$, while $8 \%-33 \%$ were LC 3 and $2(<350 \mathrm{~m})$. The lowest percentage of useable locations $(8 \%)$, belonged to the adult female. She was the first falcon to be tracked and her transmitter was the oldest model.

Preset duty cycles are intended to regulate transmitter battery usage. It can be useful to analyse how efficiently duty cycle on times are being utilised as an indication of possible 
TABLE 3: Performance measures/operating details Technical details describing all five PTT's.

\begin{tabular}{|c|c|c|c|c|c|c|c|c|c|c|c|c|}
\hline \multirow[b]{2}{*}{ Falcon $^{1}$} & \multirow[b]{2}{*}{$\begin{array}{c}\text { Duty cycle } \\
\text { (on/off) }\end{array}$} & \multirow[b]{2}{*}{ Active dates } & \multirow[b]{2}{*}{$\begin{array}{c}\text { Duration } \\
\text { (days) }\end{array}$} & \multirow[b]{2}{*}{$\begin{array}{c}\text { Duration } \\
\text { (hours) }\end{array}$} & \multirow[b]{2}{*}{$\begin{array}{c}\text { Total } \\
\text { points }\end{array}$} & \multicolumn{6}{|c|}{ Location Class (LC) } & \multirow[t]{2}{*}{$\begin{array}{c}\text { Battery } \\
(\text { voltage })^{2}\end{array}$} \\
\hline & & & & & & $3(\%)$ & $2(\%)$ & $1(\%)$ & $3,2,1(\%)$ & $0(\%)$ & A \& B (\%) & \\
\hline Juv female & $10 / 24$ & $16 / 01 / 05-15 / 05 / 05$ & 118 & 830 & 514 & 4 & 13 & 32 & 49 & 30 & 21 & $3.9 \pm .09$ \\
\hline Juv male 1 & $10 / 48$ & $18 / 12 / 05-28 / 04 / 06$ & 124 & 510 & 495 & 11 & 17 & 26 & 54 & 29 & 17 & $4.1 \pm .05$ \\
\hline Juv male 2 & $10 / 48$ & 29/01/07-17/06/07 & 140 & 580 & 460 & 13 & 20 & 20 & 53 & 24 & 23 & $4.1 \pm .13$ \\
\hline Adult female & $10 / 24$ & $18 / 02 / 02-11 / 12 / 04$ & 1027 & 7240 & 1046 & 1 & 7 & 24 & 32 & 47 & 21 & $3.8 \pm .2$ \\
\hline Adult male & $10 / 48$ & $18 / 12 / 05-09 / 08 / 08$ & 965 & 4000 & 1548 & 11 & 17 & 25 & 53 & 25 & 22 & $3.8 \pm .1$ \\
\hline
\end{tabular}

${ }^{1}$ The adult male and both juvenile males carried the newer PTT's.

${ }^{2}$ Battery (solar) voltage. Minimum value for a transmission is 3.6 volts.

TABLE 4: Accuracy and precision ${ }^{1}(\mathrm{~km})$ by Location Class (LC) from two stationary PTT's.

\begin{tabular}{lccccc}
\hline & Argos & Transmitter $1^{2}$ & Transmitter 2 \\
\hline LC $^{4}$ & Precision $(\mathrm{km})$ & $N$ & Accuracy \pm precision $(\mathrm{km})$ & $N$ & Accuracy \pm precision $(\mathrm{km})$ \\
3 & \pm 0.15 & 588 & $0.24 \pm 0.2$ & 21 & $0.52 \pm 0.2$ \\
2 & \pm 0.35 & 456 & $0.55 \pm 0.8$ & 11 & $1.06 \pm 0.6$ \\
1 & \pm 1 & 485 & $1.64 \pm 2.3$ & 6 & $1.95 \pm 0.9$ \\
0 & $>1$ & 342 & $48.64 \pm 268.2$ & 3 & $4.22 \pm 1.2$ \\
$\mathrm{~A}$ & No accuracy estimation & 366 & $21.93 \pm 170.8$ & 5 & $1.04 \pm 0.96$ \\
$\mathrm{~B}$ & No accuracy estimation & 48 & $17.41 \pm 28.4$ & 5 & $39.9 \pm 50.26$ \\
$\mathrm{Z}$ & Invalid location & $147 \pm 397.4$ & $\mathrm{n} / \mathrm{a}$ & $\mathrm{n} / \mathrm{a}$ \\
\hline
\end{tabular}

"Accuracy" (mean) is the offset, or bias, of that mean relative to the true location points, whereas "Precision" (s.d.) is a measure of the tightness of the grouping, being the clustering of points about the mean of those points [15].

${ }^{2}$ Transmitter one was tested for two and a half years. The "true" location was not known so the mean location was calculated using the set of 588 LC 3 locations $(-38.82511,176.58243)$. This transmitter had 25 locations removed of LC 3, 2, 1, A, and B. These locations either had incorrect formats or distances from the mean of $>400 \mathrm{~km}$ indicating impossible speeds and deeming them to be serious outliers.

${ }^{3}$ Transmitter two was tested for six months.

${ }^{4} \mathrm{LC} 3,2,1$, and 0 are available when 4 messages are received per satellite overpass, LC A from 3 messages and LC B from 2 messages. LC Z is considered an invalid location. See methods in text.

bias in the data. All transmitters were equipped with a 10hour on duty cycle and, using LC 3, 2, and 1 locations, the average time between the first location and last location within this duty cycle on time was four and a half hours or 270 minutes (range 172-366 minutes) with the average time between individual locations within the same duty cycle period being 99 minutes (range 86-109 minutes). From this duty cycle we got an average of seven locations per tracking day for locations of $<1000 \mathrm{~m}$ (LC 3, 2, and 1), and four per tracking day for locations $<350 \mathrm{~m}$ (LC 3 and 2).

The average voltage for all transmitters ranged between 3.8 and 4.1 (Table 3). The first location within each 10hour on phase of the duty cycle gave an average reading of $3.93 \mathrm{~V}$ (range $3.81 \mathrm{~V}-4.17 \mathrm{~V}$ ) whilst the final location average reading was $3.88 \mathrm{~V}$ (range $3.73 \mathrm{~V}-4.13 \mathrm{~V}$ ), leading to an average difference between the first and final reading voltage of $0.048 \mathrm{~V}$ (range $0.031 \mathrm{~V}-0.081 \mathrm{~V}$ ). Throughout the tracking period, the adult male and female transmitters showed no decline in voltage, the juvenile male 1 and male 2 showed only very slight declines, with the juvenile female showing a more substantial voltage decline from an average of 3.95 to $3.75 \mathrm{~V}$.

Most locations were obtained between $1600 \mathrm{~h}$ and $0600 \mathrm{~h}$ and virtually no falcons were located around midday
(Figure 3). This pattern was also evident when analysing the locations from the two stationary PTT's. These were transmitters that detached from the falcons but continued transmitting for a 30-month and a six-month period. During low PTT acquisition periods, we also observed a deterioration in location quality ratings.

We used the two stationary PTT's to test the accuracy of the system (Table 4). The results show the one-standarddeviation accuracy for LC 2 locations (the minimum location class used for ecological analysis in this study) to be 0.8 and $0.6 \mathrm{~km}$, compared to the $0.35 \mathrm{~km}$ suggested by Argos. As one of the transmitters was never recovered, the true position for that transmitter was estimated to be the mean location of the LC $3(N=588)$ locations.

\section{Discussion and Conclusions}

4.1. Technical Effectiveness. Understanding how effectively the technology functioned can provide important cues as to the quality of the data used for ecological analysis, hence improving interpretation. It can highlight areas of possible bias in the data as well as times when caution should be exercised when making assumptions that may underpin management decisions. 


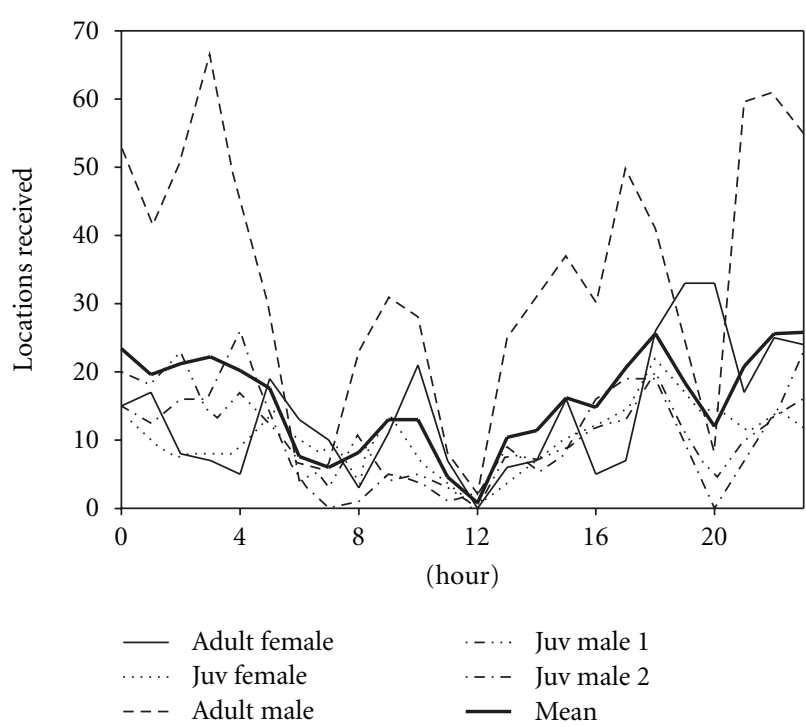

Figure 3: Locations of all five falcons showing the time of day the location was obtained.

The number of high confidence PTT locations transmitted during this study is more than that reported for similar studies. Almost $50 \%$ of the locations transmitted from four of the five units were LC 3,2, and 1 (accuracy $<1 \mathrm{~km}$ ) locations and approximately 25\% LC 3 and 2 (accuracy $<350 \mathrm{~m}$ ) (Table 3). Britten el al. [16] tracked peregrine falcons (Falco peregrinus anatum) in Alaska, Utah and Arizona and obtained $11 \%$ of LC 3, 2, and 1 locations. This was similar to Soutullo et al. [17] who tracked golden eagles (Aquila chrysaetos) and Bonelli's eagles (Hieraaetus fasciatus) throughout the Iberian peninsula obtaining less than $10 \%$ of LC 3, 2, and 1 locations. Ganusevich et al. [18] tracked peregrine falcons in northern Russia and obtained an average of 52\% LC 3, 2, 1, and 0 locations, whilst Nicholls et al. [19] tracked albatrosses, petrels and shearwaters using Argos and obtained approximately 13\% LC 3, 2, and 1 locations. Meyburg and Fuller [20] report that for most bird tracking studies LC 2 and 3 locations occur approximately 10\%-15\% of the time. If the number of LC 3, 2, and 1 location points is insufficient, it is possible to use LC 0 locations, provided appropriate filtering methods are used [15]. However, given the frequency of high quality location transmissions in this study, it was not necessary to use LC 0 locations.

For most of the time all the solar-charged batteries remained well charged indicating that the forested environment of Kaingaroa did not impede the charging of the solar array or the efficiency of the duty cycle. The average voltage readings for each of the transmitters (Table 3) was higher than required for operating. The difference in the charge of the units between the start and completion of the cycle was low with the transmitters holding an average charge of 3.9 V (range 3.7 V-4.1 V) for each final location reading. The minimum requirement for successful location acquisition is $3.6 \mathrm{~V}$ for both the 12 and $18 \mathrm{~g}$ transmitters; therefore, it is possible we could have utilised a longer on time during the duty cycle, such as 14 hours on/24 hours off, thereby increasing the number of locations obtained for analysis. With no declines in the units' charge just prior to going offline, it is reasonable to assume that the battery was unlikely to have contributed towards PTT transmission failures.

Most of the location points for this study were recorded between 1600 and 0600 hours (Figure 3), even though the interval between NOAA satellite overpasses over Kaingaroa Forest was evenly spaced throughout the day. The one anomaly with the satellite overpasses in this area was reduced satellite reception around local noon, a known phenomenon in the Southern Hemisphere [21]. As this location acquisition time pattern was observed on both our moving birds and stationary transmitters it would appear that this is likely associated with technical issues related to the Argos system rather than the behaviour of the falcons.

Behavioural issues, however, should still be considered as possible reasons for lower number and quality of locations. There were fewer quality locations received during the day $(0600$ and $1600 \mathrm{~h})$ when more movement is expected. Consistent with that, Kenward [22] noted that movement can cause accuracy errors of approximately $100 \mathrm{~m}$ for each $\mathrm{km} \mathrm{h}^{-1}$ of movement, thus the location error could be up to $4 \mathrm{~km}$ for a bird flying at $40 \mathrm{~km} \mathrm{~h}^{-1}$. The Argos system does not correct for this movement error, therefore, PTT's moving while transmitting may incorrectly report the accuracy class due to instability during location calculation. This issue, along with thick vegetation blocking the signal, indicates that bias will tend towards places and activities where the location quality is higher and away from identifying any hunting behaviour when fast flying is occurring or resting sites obscured from satellite reception.

The location accuracy of Argos was tested using two stationary PTT's and the results are presented in Table 4. Whilst these reveal a pattern of improvement reflected in the higher confidence LC classes, they show larger errors than those quoted by Argos [11]. Transmitter 2 is shown to be more reliable than transmitter 1 . However, the true location point calculated from transmitter 1 was estimated from the mean of known Argos locations rather than identifying its true location. Also, the results may not be representative of moving birds due to the effect on accuracy from fast flying [22], and that both transmitters were stationary during this test. Thus, the error and the Argos positions for the two stationary transmitters is likely an underestimate of the error for the moving falcons.

Our results compare to Hyrenbach et al. [23] who tracked black-footed albatrosses (Phoebastria nigripes) off central California obtaining errors of $0.44 \mathrm{~km}$ (LC 3), $0.73 \mathrm{~km}$ (LC 2), and $1.53 \mathrm{~km}$ (LC 1). Nicholls and Robertson [15], who undertook a comprehensive study of the location accuracy of PTT's, found that accuracy and precision errors were also larger than those stated by Argos. Their analysis revealed that poorer quality locations (LC 0, A, B, and Z) resulted from poor satellite reception as well as inaccuracies due to elliptical rather than circular orbits.

For the most part, PTT/Argos technology allowed us to achieve our research objectives. However, there are problems with using Argos satellite technology for tracking 
fine scale movements. These result from low and uncertain accuracy, the inability to detect travel speed, the irregularity of acquisition times, and possible bias from unsuccessful locations caused by either fast flying movement or rest areas obscured by scrub or bush. Because of these issues it was also difficult to ascertain whether the location of a falcon implied occupation or just a momentary passing over.

For studies that do require finer scale analysis we recommend the use of GPS technology if the field conditions allow for it. GPS technology has the advantage of providing many highly accurate location and speed calculations obtained on a regular schedule. This can enable detailed movement patterns to be identified, and if the Argos system is used as the download method, it can be very cost efficient over the long-term. However, GPS does require a clear horizon to enable full view of the satellites, which can be compromised by diverse vegetation or mountain ranges [24]. Given that Kaingaroa Forest has a number of mature pine compartments that are densely forested, it may not be appropriate for GPS technology to be used in this environment until further advances have been made. In addition to transmission problems, the New Zealand falcon may be too small to wear the slightly heavier GPS transmitters currently available. However, given that the solar charged batteries used in the Argos transmitters performed well in this environment, the use of future smaller solar units should be considered.

4.2. Ecological Outcomes. The MCP home ranges of the female and male adult falcons tracked over the three years of this study were 147 and $61 \mathrm{~km}^{2}$, respectively, whilst the $95 \%$ kernel home ranges were 90 and $8 \mathrm{~km}^{2}$, respectively (Table 1). The male generally remained within $4 \mathrm{~km}$ of his original nest site. The female falcon also remained close to her nest, with each successive nest located on average $5 \mathrm{~km}$ apart and no more than $7.5 \mathrm{~km}$ apart during the three years. For both the male and female, the home ranges were larger than those suggested by Seaton [9] who reported the mean adult female and male 95\% MCP within Kaingaroa Forest as $6.15 \mathrm{~km}^{2}$ and $9.23 \mathrm{~km}^{2}$, respectively. The variation in results may be attributed to the use of a different tracking method as well as home range calculation. Seaton [6] used VHF tracking to obtain a relatively low number of location points during a short time period and this can understate a home range when compared with results from continuous satellite tracking methods. However, our home ranges were similar to those suggested by Fox [7] who reported the MCP home range of adult Eastern falcon pairs within South Island indigenous forest to be $75 \mathrm{~km}^{2}$. It is thought that home ranges within indigenous forests are larger than in pine plantations because prey are less abundant [25].

The 95\% kernel home range of the three juveniles was $44 \mathrm{~km}^{2}$ (female), $412 \mathrm{~km}^{2}$ (male 1), and $12 \mathrm{~km}^{2}$ (male 2). Juvenile male 1 had an unusually large home range consisting of three distinct high use areas. Two of these were located within Kaingaroa Forest and the third was in a pine forest approximately $50 \mathrm{~km}$ away (Figure 1). Tracking the falcons revealed that all three juveniles left the forest at some point.
This is consistent with Seaton's [6] finding that 90\% of juvenile birds left the forest at some time during their first autumn and winter, mostly on short visits to adjacent farmland.

We had expected this diurnal species to remain near the nest after dark. However, they were not noticeably closer to the nest during the night than at other times and their nighttime home ranges were either similar to or larger than during daylight hours. It should be noted, however, that aside from increased movement, the larger home range identified during the night may have resulted from the larger number of locations obtained during this time (Figure 3 ).

Juvenile falcons fledge at around 34 days after hatching [26], with all three juveniles in this study caught and tagged at around 75 days old. During the first month after fledging, juveniles are thought to defend the nest area actively, after which time this defense declines [26]. Based on a dispersal distance of $>4 \mathrm{~km}$ from the nest, the juvenile female left her natal home range 68 days after fledging and the males at 69 and 58 days. Similarly, Seaton [6] reports that the juveniles tracked in his study dispersed out of the natal home range an average of 76 days after fledging, with the first females dispersing at 56 days and the first males at 42 days. His study, however, used a smaller dispersal distance of $>1.7 \mathrm{~km}$ to infer dispersal, due to the apparently smaller adult home ranges in his study. Around the time of natal dispersal, juvenile mortality is high for many falcon species [27]. Seaton [6] suggests that the distances and timing of natal dispersal are highly variable and influenced by factors such as parental aggression, brood size, weather, and prey density. There is also evidence to suggest that the dispersal for this species may be initiated later in indigenous forests than plantation forests $[28,29]$. This may be attributable to the higher density of food in plantation forests, allowing for hunting skills to develop at a faster rate within these forests, leading to earlier independence from adults [6].

Seaton [9] reports that adult falcons prefer stands $<4$ years and $>20$ years, however, our findings do not support this. We found that falcons use compartments of all ages in proportion to their availability (Table 2 ). This does not mean that selection was not occurring but that more accurate GPS transmitters and a larger sample size are needed to be more confident about falcons' compartment selection behaviour. It is also thought falcons prefer to hunt along the edges of older aged stands due to the high availability of prey along the ecotone between plantation compartments of old and young trees [9]. However, due to the small width size $(25-30 \mathrm{~m})$ of an ecotone, we would not be able to determine this without the use of finer scale tracking methods.

From our study we found: home ranges varied for both adults and juveniles; juveniles remain in the forest after dispersal, suggesting that sufficient resources are available; juveniles spend the first two and a half months after fledging within ca. $8 \mathrm{~km}$ of their nest; one of the juveniles left Kaingaroa Forest after two and a half months, flew directly to an adjacent plantation forest, before returning to Kaingaroa Forest; and finally the variance in ages of compartments selected by falcons indicates that all stand ages provide important habitat for falcons and whilst four of the five 
falcons visited areas outside the forest, they all returned to Kaingaroa.

We found that Argos satellite technology performed well and the collection of continuous data on falcon movement has refined our understanding of the ecology of the species. Our results highlight the importance of plantation forests to the New Zealand falcons and of forestry management practises that maintain a mosaic of different aged pines.

\section{Acknowledgments}

The authors gratefully acknowledge the invaluable contribution by the following organisations and individuals: New Zealand Lotteries Grants Board, Noel Hyde and Debbie Stewart (Wingspan Bird of Prey Trust), Steve Lawrence and Chris Gay (Raptor Association of New Zealand), Colin Maunder and GIS Group (Kaingaroa Timberlands Ltd), Rob Murray, Mathew Irwin, Mike Tuohy, Mark Coetzee, Denise Stewart, Richard Seaton, Andy Thomas, James Crowe and Nic Addison (Massey University), Microwave Telemetry, and Mathieu Lecointe (CLS Argos).

\section{References}

[1] C. M. Miskelly, J. E. Dowding, G. P. Elliott et al., "Conservation status of New Zealand birds, 2008," Notornis, vol. 55, no. 3, pp. 117-135, 2008.

[2] B. D. Heather and H. A. Robertson, The Field Guide to the Birds of New Zealand, Oxford University Press, New York, NY, USA, 1996.

[3] "Birdlife International Falco novaeseelandiae," in: IUCN 2009. IUCN Red List of Threatened Species. Version 2009.1, 2009, http://www.iucnredlist.org.

[4] D. Stewart and N. Hyde, "New Zealand falcons (Falco novaeseelandiae) nesting in exotic plantations," Notornis, vol. 51, no. 2, pp. 120-121, 2004.

[5] N. J. Addison, J. D. Holland, and E. Minot, "The adoption of pine plantations by New Zealand Falcon (Falco novaeseelandiae) in the Hawkes Bay, New Zealand," New Zealand Journal of Forestry, vol. 51, pp. 3-7, 2006.

[6] R. Seaton, J. D. Holland, E. O. Minot, and B. P. Springett, "Natal dispersal of New Zealand falcon (Falco novaeseelandiae) in plantation forests," Notornis, vol. 55, no. 3, pp. 140-145, 2008.

[7] N. C. Fox, The biology of the New Zealand falcon (Falco novaeseelandiae Gmelin 1788), Unpublished Doctoral Thesis, University of Canterbury, Christchurch, New Zealand, 1977.

[8] J. D. Holland and R. R. McCutcheon, "Satetlite tracking a New Zealand falcon (Falco novaeseelandiae)," Notornis, vol. 54, no. 1, pp. 20-27, 2007.

[9] R. Seaton, The ecological requirements of the New Zealand falcon (Falco novaeseelandiae) in plantation forestry, Unpublished Doctoral Thesis, Massey University, Palmerston North, New Zealand, 2007.

[10] J. Boyd, Pumice \& Pines. The Story of Kaingaroa Forest, Wellington, New Zealand, GP Publications, 1992.

[11] Argos User's Manual, 2007, http://www.argos-system.org/manual/.

[12] P. H. Bloom, W. S. Clark, and J. W. Kidd, "Capture techniques," in Raptor Research and Management Techniques, D. M. Bird and K. L. Bildstein, Eds., pp. 193-219, Hancock House Publishers, BC, Canada, 2007.
[13] R. E. Kenward, R. H. Pfeffer, M. A. Al-Bowardi et al., "Setting harness sizes and other marking techniques for a falcon with strong sexual dimorphism," Journal of Field Ornithology, vol. 72, no. 2, pp. 244-257, 2001.

[14] P. N. Hooge and B. Eichenlaub, "Animal movement extension to ArcView. Version 1.1," in US Geological Survey, Alaska Biological Science Center, Anchorage, AK, USA, 1997.

[15] D. G. Nicholls and C. J. R. Robertson, "Validating locations from CLS: Argos satellite telemetry," Notornis, vol. 54, no. 3, pp. 121-136, 2007.

[16] M. W. Britten, P. L. Kennedy, and S. Ambrose, "Performance and accuracy evaluation of small satellite transmitters," Journal of Wildlife Management, vol. 63, no. 4, pp. 1349-1358, 1999.

[17] A. Soutullo, L. Cadahía, V. Urios, M. Ferrer, and J. J. Negro, "Accuracy of lightweight satellite telemetry: a case study in the Iberian Peninsula," Journal of Wildlife Management, vol. 71, no. 3, pp. 1010-1015, 2007.

[18] S. A. Ganusevich, T. L. Maechtle, W. S. Seegar et al., "Autumn migration and wintering areas of Peregrine Falcons (Falco peregrinus) nesting on the Kola Peninsula, northern Russia," Ibis, vol. 146, no. 2, pp. 291-297, 2004.

[19] D. G. Nicholls, C. J. R. Robertson, and M. D. Murray, "Measuring accuracy and precision for CLS. Argos satellite telemetry locations," Notornis, vol. 54, no. 3, pp. 137-157, 2007.

[20] B.-U. Meyburg and M. R. Fuller, "Satellite Tracking," in Raptor Research and Management Techniques, D. M. Bird and K. L. Bildstein, Eds., pp. 242-248, Hancock House Publishers, BC, Canada, 2007.

[21] D. G. Nicholls and C. J. R. Robertson, "Assessing flight characteristics for the Chatham albatross (Thalassarche eremita) from satellite tracking," Notornis, vol. 54, no. 3, pp. 168-179, 2007.

[22] R. E. Kenward, A Manual for Wildlife Radio Tagging, Academic Press, London, England, 2001.

[23] K. D. Hyrenbach, C. Keiper, S. G. Allen, D. G. Ainley, and D. J. Anderson, "Use of marine sanctuaries by far-ranging predators: commuting flights to the California current system by breeding Hawaiian albatrosses," Fisheries Oceanography, vol. 15, no. 2, pp. 95-103, 2006.

[24] B. Cargnelutti, A. Coulon, A. J. M. Hewison, M. Goulard, J.M. Angibault, and N. Morellet, "Testing Global Positioning System performance for wildlife monitoring using mobile collars and known reference points," Journal of Wildlife Management, vol. 71, no. 4, pp. 1380-1387, 2007.

[25] M. N. Clout and P. D. Gaze, "Effects of plantation forestry on birds in New Zealand," Journal of Applied Ecology, vol. 21, no. 3, pp. 795-815, 1984.

[26] S. Marchant and P. J. Higgins, Handbook of Australian, New Zealand and Antarctic Birds, Oxford University Press, Melbourne, Australia, 1993.

[27] I. Newton, Population Ecology of Raptors, T \& AD Poyser, Berkhamsted, London, UK, 1979.

[28] S. B. Lawrence and C. G. Gay, "Behaviour of fledgling New Zealand falcons (Falco novaeseelandiae)," Notornis, vol. 38, pp. 173-182, 1991.

[29] L. P. Barea, Habitat use, diet, and nest site selection of forestdwelling New Zealand falcons, Unpublished Masters Thesis, University of Waikato, Cambridge, New Zealand, 1995. 

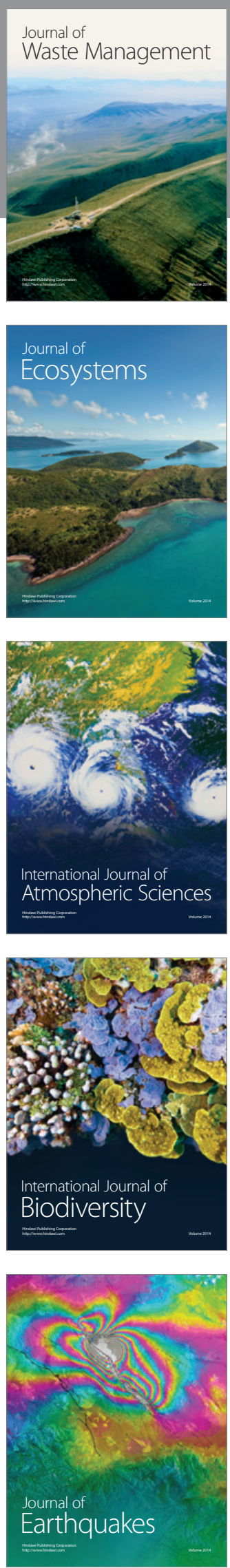
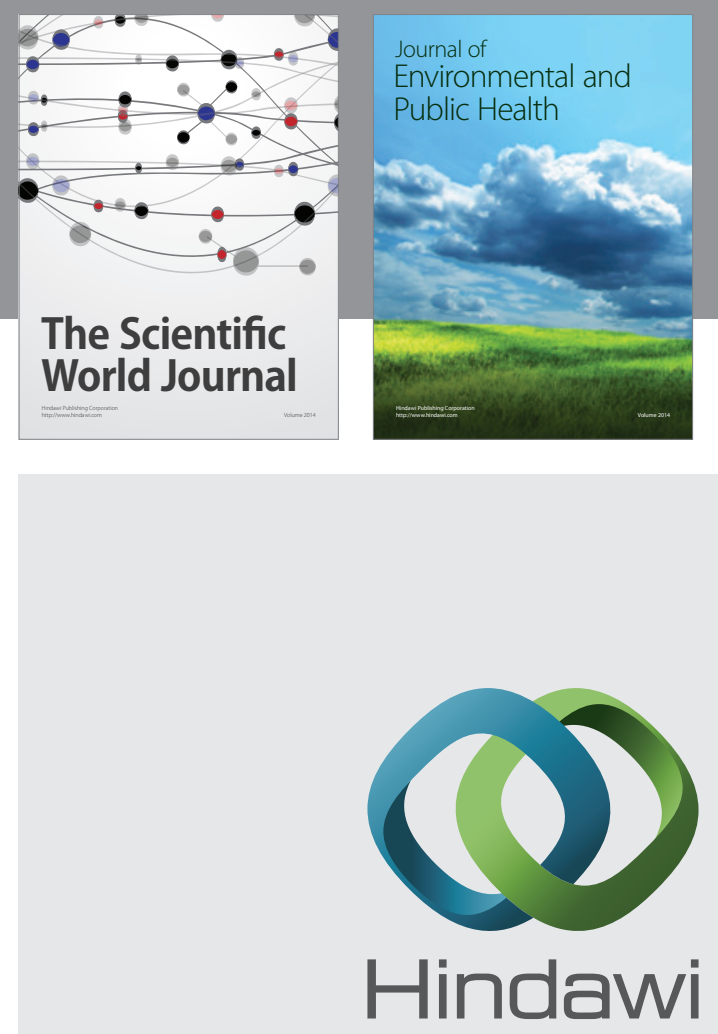

Submit your manuscripts at

http://www.hindawi.com
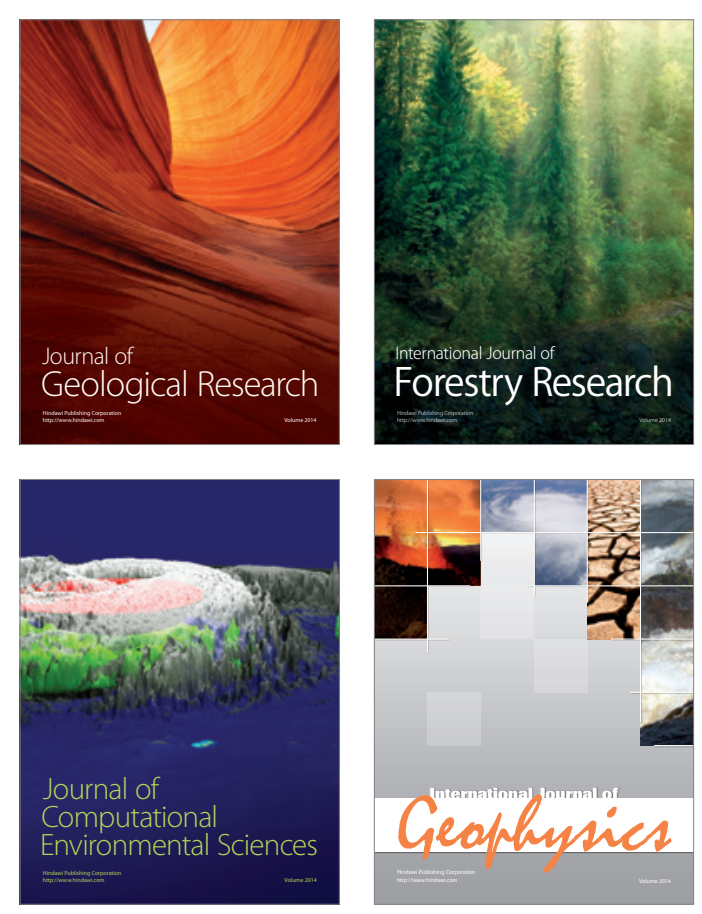
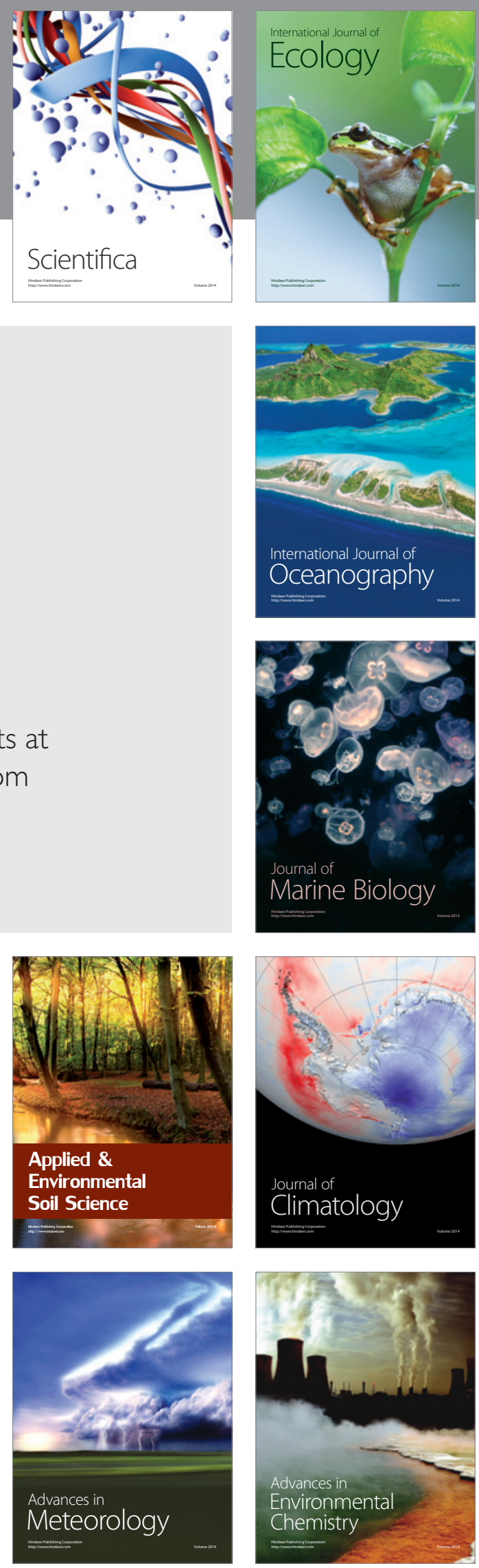